\title{
"É cada um para o que nasce?": Desenvolvimento das atribuições causais da pobreza infantil na infância e soluções percebidas para a pobreza
}

\author{
Leonor Pereira da Costa ${ }^{1,2}$, Ricardo Borges Rodrigues ${ }^{1}$ \& Sven Waldzus ${ }^{1}$ \\ ${ }^{1}$ Iscte-Instituto Universitário de Lisboa \\ 2 Universidade Lusófona, HEI-Lab
}

\begin{abstract}
Resumo: O presente estudo analisa o desenvolvimento das atribuições causais da pobreza infantil, o papel do estatuto sócio económico nestas atribuições e as soluções que as crianças identificam para a pobreza. Foram entrevistadas crianças com idades entre os 6 e 12 anos $(N=107)$, e os resultados mostram a prevalência da externalização das causas da pobreza, nomeadamente através de explicações fatalistas (e.g. sorte) e estruturalistas (e.g. desemprego). Este estudo permite, ainda, verificar que as crianças percecionam dois tipos de soluções para a pobreza, que variam no grau de agência imputado à criança pobre. Análises de mediação mostram que a indicação de soluções que requerem a ação da criança pobre aumenta com a idade através do aumento da perceção de que a pobreza é causada por fatores sociais. Os resultados são discutidos em termos do desenvolvimento sociocognitivo, refletindo sobre as consequências das atribuições causais da pobreza na perpetuação das desigualdades sociais.
\end{abstract}

\section{Palavras-chave: Crianças; atribuições causais da pobreza; pobreza infantil; soluções para a pobreza.}

Development of causal attributions of child poverty and perceived solutions to poverty in childhood: This study investigates the development of causal attributions of child poverty in childhood, the role of socio-economic status in these attributions, and the solutions that children identify for poverty. Children aged 6 to 12 years were interviewed $(N=107)$. The results show the prevalence of external attributions of causes of poverty, namely through fatalistic (e.g., luck) and social (e.g., unemployment) explanations. This study also identifies two types of children's suggestions of solutions to poverty, which vary in the degree of agency attributed to poor children. Mediation analyzes show that indicating solutions that require the action of the poor child increases with age via an increase in the belief that poverty is caused by social factors. The results are discussed in terms of socio-cognitive development and in terms of the consequences of causal attributions of child poverty in the perpetuation of social inequalities.

\section{Keywords: Children; causal attributions of poverty; child poverty; solutions to poverty.}

Nos últimos quinze anos a taxa de pobreza infantil cresceu em alguns dos países da Organização para a Cooperação e Desenvolvimento Económico (OCDE; e.g., Portugal, Grécia, Itália, Lituânia), não obstante os esforços desenvolvidos no sentido da erradicação da pobreza. Dados recentes indicam que cerca de 13\% das crianças dos países da OCDE são pobres, sendo a taxa em Portugal igual a 16\% (OCDE, 2017).

A privação económica e material sentida pelos indivíduos em condição de pobreza é, frequentemente, acompanhada de processos de estigmatização e exclusão social (Lott, 2002; Ridge, 2002). As consequências da estigmatização social são múltiplas, podendo conduzir a processos de introjeção do estigma acompanhados da rejeição das identidades estigmatizadas e de baixa-autoestima (França \& Monteiro, 2002). Vários estudos indicam que as crianças em situações de pobreza afirmam serem vítimas de bullying, e que atribuem essa circunstância à sua situação económica (Crowley \& Vulliamy, 2007), em particular quando vivem em áreas mais afluentes (Hooper et al., 2007). Existe, ainda, evidência que, em bairros marginalizados, a perceção de discriminação das crianças com base na situação económica está associada a níveis inferiores de bem-estar subjetivo, compromete a sua integração escolar e a perceção de segurança (Bradshaw et al., 2016).

\footnotetext{
${ }^{1}$ Morada para correspondência: Leonor Pereira da Costa, CIS-IUL - Centro de Investigação e Intervenção Social, Edifício ISCTE - IUL, Av. das Forcas Armadas, 1649-026 Lisboa. E-mail: leonor_pereira_costa@iscte-iul.pt.

Este trabalho é parte integrante do doutoramento de Leonor Pereira da Costa, sob orientação de Ricardo Borges Rodrigues e Sven Waldzus. 0 doutoramento foca-se no desenvolvimento da auto-categorização segundo a classe social na infância, e o seu papel na inclusão e exclusão de crianças pobres. Este trabalho foi financiado com uma Bolsa de Doutoramento pela Fundação para a Ciência e Tecnologia (SFRH/BD/99553/2014). Os autores agradecem profundamente à Professora Maria Benedicta Monteiro pelo fundamental contributo que deu à Psicologia Social do desenvolvimento em Portugal, nomeadamente para a literatura no domínio do desenvolvimento e redução do preconceito intergrupal na infância, onde se centra a nossa pesquisa.
} 
Paralelamente ao desenvolvimento do conhecimento de outras categorias sociais salientes, como a idade, sexo e grupo racial (Nesdale, 2004; Monteiro, 2002), a consciência da categoria de classe social emerge entre os 3 e os 5 anos de idade, designadamente com a distinção entre 'ricos' e 'pobres' estabelecida a partir de elementos materiais e simbólicos observáveis, como a roupa ou outros bens (Leahy, 1981; Ramsey, 1991). Um estudo realizado em Portugal com crianças Brancas, Negras e Roma com 6-8 anos e 912 anos avaliou o estatuto social subjetivo de cada grupo (Feddes et al., 2014). Os resultados confirmam que as crianças reconhecem, desde os 6-8 anos de idade, as assimetrias de estatuto social que existem na sociedade (Correia et al., 2007; Vala et al., 2004). Neste caso, são as crianças Roma aquelas cujo estatuto social é percebido como inferior, e igualmente aquelas que recebem avaliações menos favoráveis dos seus pares Brancos e Negros. O estudo mostra ainda a centralidade do estatuto subjetivo, enquanto fator mediador das variações etárias registadas nas preferências sociais e na atribuição de traços aos diferentes grupos. É de realçar aqui, que estatísticas recentes mostram que, na Europa, em média 80\% da comunidade Roma vive em risco de pobreza (FRA, 2018), podendo efetivamente existirem vários fatores que confluam para atitudes mais negativas perante este grupo.

Uma variável importante no processo de estigmatização dos pobres diz respeito às explicações que os indivíduos mobilizam na análise do fenómeno da pobreza. 0 estudo das atribuições causais da pobreza tem merecido alguma atenção nas ciências sociais, particularmente com a população adulta, dada a evidência de que estas se encontram associadas às atitudes e comportamentos face aos pobres (Bullock, 1999; Cozzarelli et al., 2001; Tagler e Cozzarelli, 2013).

A literatura identifica três tipos de atribuições causais à pobreza, nomeadamente "individualista", "estruturalista" e "fatalista" (Bullock, 1999; Cozzarelli et al., 2001). Nas atribuições individualistas a causa da situação de pobreza é interna, concretamente o comportamento do indivíduo (e.g., más escolhas, incompetência, preguiça). Em contraste, nas atribuições estruturalistas, a explicação da situação reconhece o papel de fatores sociais, externos ao indivíduo, como por exemplo desemprego estrutural, oportunidades desiguais, entre outros. Finalmente, nas atribuições fatalistas a pobreza é explicada como resultado do destino, de acontecimentos ou acidentes alheios ao indivíduo ou à própria sociedade (e.g., doença, azar).

Vários estudos têm mostrado que, em adultos, as atribuições causais individualistas da pobreza são acompanhadas de atitudes menos favoráveis face a políticas de apoio e combate à pobreza (e.g., Weiner et al., 2011). Em linha com estes resultados, outros estudos mostram ainda que as atribuições individualistas face aos pobres estão associadas a estereótipos negativos face a este grupo social, descritos como "preguiçosos", "sujos", "fracos" ou "desmotivados" (Bullock, 1999; Cozzarelli et al., 2001). Com crianças, existe evidência de que o desenvolvimento de crenças essencialistas sobre determinados membros do grupo tem um impacto negativo imediato no comportamento face aos mesmos, nomeadamente em tarefas de distribuição de recursos (Rhodes et al., 2018).

A pesquisa sobre atribuições causais à pobreza tem sido realizada, quase exclusivamente, com adultos, embora seja relevante questionar de que modo se expressa este processo na infância, sobretudo atendendo à evidência de que as crianças aos 6 anos de idade apresentam atitudes menos favoráveis face aos pobres (Feddes et al., 2014), e estereótipos negativos aos 10-11 anos (Sigelman, 2013; Woods et al., 2005).

A literatura sobre o desenvolvimento cognitivo da atribuição causal na infância, focando outros domínios que não o da pobreza, tem analisado a expressão de dois tipos de atribuições na explicação do comportamento dos indivíduos, diferindo no locus da causalidade: um que sinaliza o papel das entidades externas ao indivíduo, e o outro que salienta a importância dos fatores internos ao indivíduo. Nesta literatura, a evidência sugere que, entre os 4 e 6 anos de idade, as crianças não só são capazes de realizar atribuições a fatores externos ao indivíduo, como ao contexto (Ruble et al., 1979), como apresentam um viés que favorece estas explicações externas em detrimento das individualistas (Higgins \& Bryant, 1982; Miller \& Aloise, 1989). É mais tarde na infância, que se dá a mudança das explicações externas e situacionais para atribuições internas. Segundo Rholes e Ruble (1984), as crianças com idade inferior a 8 anos dificilmente explicam os comportamentos daqueles que as rodeiam a partir de traços estáveis e individuais. Na mesma linha, um outro estudo, mostra, que a explicação espontânea dos comportamentos a partir dos traços dos indivíduos só acontece por volta dos 9-10 anos, e que as crianças de 5-6 anos apoiam a sua avaliação na valência associado ao próprio alvo, i.e. bom/mau (Alvarez et al., 2001).

No domínio específico da pobreza e das perceções sobre as pessoas pobres, os resultados estão em linha com a precedência das atribuições externas face às internas. Segundo Sigelman (2013), uma grande parte das crianças com seis anos não conseguiu atribuir causas à pobreza, contudo, quando o fizeram, a maioria atribuiu causas sociais, nomeadamente a falta de um (bom) emprego, tendo esta perceção aumentado com a idade. Leahy (1981) defende que, com a idade, se verifica uma tendência para que as explicações das diferenças entre 'ricos' e 'pobres' se deixem de dever apenas a fatores externos e observáveis, mas também a diferenças individuais relacionadas com traços de personalidade. 
Efetivamente, é apenas entre os 8-10 anos de idade que as crianças começam a considerar características como esforço, perseverança e aptidões sociais ou intelectuais quando falam sobre as pessoas pobres (Leahy, 1983; Sigelman, 2012). Ainda, Enesco e Navarro (2003) referem que apenas a partir dos 8 anos as crianças tomam consciência que os trabalhos não são todos iguais e que existem uns mais importantes, mais difíceis, ou mais necessários do que outros, pelo que as pessoas que realizam estes trabalhos devem ser melhor remuneradas; ainda, e que a partir dos 10 anos associem qualidades como esforço, persistência e exigência pessoal ao facto de se conseguir um bom trabalho.

Contudo, em contraponto a estes resultados, estudos mais recentes (Hussak \& Cimpian, 2015; 2018) mostram que a partir dos 4 anos de idade as crianças justificam as desigualdades sociais referindo-se a atributos inerentes aos indivíduos, havendo evidência ainda que esta tendência implícita para explicar os fenómenos com base em aspetos inerentes aos indivíduos diminui com a idade (Cimpian \& Steinberg, 2014).

Em termos de desenvolvimento sociocognitivo, a tomada de perspetiva social, isto é, a aquisição da capacidade de compreensão das situações, pensamentos e intenções dos outros indivíduos (Carlo, 2006), é essencial para o avanço de explicações para este fenómeno social. A literatura neste domínio mostra que a tomada de perspetiva social aumenta com a idade (Miller \& Aloise-Young, 2018) e aumenta também em função da experiência social da criança (Abrams et al., 2009). Assim, esta capacidade crescente de compreensão do outro e das diferentes situações em que se encontra, possibilita a contextualização do problema em questão e permite que as crianças considerem outras causas, externas ao próprio individuo, explicativas do fenómeno de pobreza. Em consonância, estudos centrados nas atribuições causais da pobreza na infância mostram que, em termos de prevalência, a atribuição causal mais mencionada é aquela que sinaliza o papel de fatores sociais externos. Por exemplo, com crianças Colombianas com 4-7 anos de idade, Amar e colegas (2015) verificaram serem mais prevalentes as explicações da pobreza com base em fatores como a falta de recursos materiais ou suporte social. Em acordo, com uma amostra de crianças Finlandesas com idades entre os 11 e os 15 anos, Hakorvita e Kallio (2016) embora registando a presença de atribuições individualistas à pobreza (e.g., má gestão financeira, preguiça, consumos ilícitos, etc.), verificaram que a maioria das crianças identifica causas de ordem social (e.g., desemprego, salários baixos, etc.).

No que respeita às soluções para a pobreza, a literatura é escassa sobre esta matéria. Chafel e Neitzel (2005) perguntaram a crianças com 8 anos de idade o que teria de acontecer para que deixassem de haver pessoas pobres. Os resultados indicam que grande parte das crianças (48\%) mencionam esforços filantrópicos para ajudar os pobres, $20 \%$ mencionam que são necessárias mudanças sociais, $11 \%$ que os próprios pobres necessitam de agir e $8 \%$ de que algum milagre poderia acontecer. Contudo, este estudo não estudou a relação destas soluções com as perceções das causas da pobreza. Com relevância na investigação desta relação, estudos de Hussak e Cimpian $(2015 ; 2018)$ mostram ainda que a internalização dos comportamentos dos indivíduos é preditor da perceção das desigualdades como justas e legítimas, apoiando o status quo (Hussak \& Cimpian, 2015). Mais ainda, as crianças entre 4 e 7 anos tendem a adotar perspetivas mais conservadoras de aceitação de políticas e tradições vigentes quando os fenómenos sociais são explicados por condições inerentes aos indivíduos: as crianças que explicaram as desigualdades sociais com base em aspetos internos aos indivíduos, perceberam estas desigualdades como aceitáveis e que nada devia ser feito para as combater (Hussak \& Cimpian, 2018).

Os estudos aqui referidos abordam a perceção das crianças sobre a pobreza em geral, não focando a pobreza infantil, e tendem a não enquadrar as atribuições causais no quadro do desenvolvimento sociocognitivo na infância. Para além disso, é muito escassa a literatura sobre as soluções que as crianças identificam como necessárias para a erradicação da pobreza.

Deste modo, o presente estudo propõe-se analisar o desenvolvimento das atribuições causais da pobreza infantil em crianças com idades entre os 6 e os 12 anos, e o papel do estatuto sócio económico neste processo. Ainda, pretende identificar as soluções que as crianças avançam para a pobreza e se estas se relacionam com as atribuições causais.

Embora a literatura apresente resultados contraditórios, existe alguma evidência em apoio à hipótese de que a expressão de atribuições externas tende a preceder a expressão de atribuições individualistas, e que a sua prevalência relativa pode aumentar com a idade fruto de um processo crescente de socialização em contexto escolar e familiar para a problemática da pobreza. Aliás, neste sentido é, ainda, expectável que o número e a diversificação de causas atribuídas à pobreza em cada criança aumentem com a idade. Relativamente às atribuições causais individualistas, a literatura é, marcadamente, contraditória; sugere, por um lado, que a sua ocorrência poderá ter lugar no período final da infância, e devido à incapacidade das crianças atribuírem traços disposicionais numa fase anterior (e.g. Miller \& Aloise, 1989); por outro lado, permite admitir que a expressão destas atribuições seja, na verdade, mais precoce, diminuindo a sua importância relativa com a idade (Cimpian \& Steinberg, 2014). Admitimos, ainda, que a 
diminuição das atribuições individualistas traduza um fenómeno de inibição ou ocultação da sua expressão. Aliás, um número muito alargado de estudos conduzidos em Portugal tem, sistematicamente, demonstrado que embora as crianças reconheçam aos 6 anos de idade ser anti normativa a expressão de preconceito (racial), a gestão adequada do comportamento de acordo com o contexto efetiva-se mais tarde, em torno dos 9-10 anos (França \& Monteiro, 2013; Monteiro et al., 2009; Rodrigues et al., 2012; Rodrigues et al., 2016 ).

No que se refere ao nível socioeconómico dos participantes, a literatura não esclarece o seu, eventual, papel na modelação das perceções das causas da pobreza. No entanto, é possível admitir que, fruto de um maior contacto com a problemática da pobreza por parte das crianças com um NSE mais baixo, estas possam apresentar um número e diversificação superiores de causas para a pobreza infantil.

Finalmente, em relação ao desenvolvimento das perceções das crianças sobre as soluções para a saída da pobreza infantil ao longo da infância e o papel das atribuições causais neste processo, o estudo adota uma abordagem essencialmente exploratória atendendo à ausência de literatura sobre esta temática. Não obstante, apoiando-nos nos resultados de Hussak e Cimpian (2018) que mostraram existir uma associação entre a expressão de atitudes protopolíticas conservadoras e a expressão de causas inerentes aos indivíduos, em geral, podemos antecipar que as crianças coordenem o tipo de soluções para a pobreza com as atribuições causais. Assim, esperamos que as crianças que mobilizam atribuições individualistas para a explicar a pobreza, apresentem soluções em que a própria criança pobre deverá ser o agente da sua mudança e, por outro lado, crianças que explicam a pobreza por fatores sociais, apresentem soluções para saída da pobreza externas à criança.

\section{MÉTODO}

\section{Amostra}

Foram entrevistadas 107 crianças entre os 6 e os 12 anos de idade $(M=9.10 ; D P=2.19)$ de dois agrupamentos de escolas públicas de Lisboa. Um dos agrupamentos onde foi realizado o estudo abrange uma população de um meio socioeconómico mais desfavorecido $(N=49 ; 46 \%)$. Neste agrupamento, 67\% $(n=33)$ das crianças inquiridas eram apoiadas pela Ação Social Escolar (ASE) ${ }^{2}$. No outro agrupamento $(n$ = 58; 54\%), a população abrangida é proveniente de um meio socioeconómico mais afluente, e apenas $10 \%$ $(n=6)$ das crianças beneficiavam do ASE. As crianças foram entrevistadas em meio escolar, após consentimento informado dos encarregados de educação.

\section{Metodologia de recolha dos dados e Procedimento}

O estudo tem como principal objetivo investigar o desenvolvimento das atribuições causas da pobreza infantil na infância. Deste modo, foram realizadas entrevistas semiestruturadas em que se colocaram três questões essenciais: uma primeira referente à perceção das crianças sobre as causas da pobreza - "O que é que achas que aconteceu para que esta criança seja pobre?" -, uma segunda relativamente à perceção sobre a persistência da pobreza - "Achas que ela vai ser para sempre pobre ou pode deixar de ser pobre?" - e, na circunstância de responderem que podem deixar de ser pobres, uma terceira questão sobre as soluções para o deixarem de ser - "O que é que tem de acontecer para eles deixarem de ser pobres?".

As crianças foram entrevistadas individualmente numa sala isolada da escola e apenas com um investigador presente, que neste caso foi a primeira autora. A entrevista durou em média 30 minutos uma vez que este estudo se insere num estudo mais alargado sobre as perceções da pobreza infantil na infância. As entrevistas foram gravadas em formato de áudio e foram posteriormente transcritas na íntegra pela primeira autora.

\section{Análise dos dados}

A análise dos dados foi realizada através da análise de conteúdo das entrevistas (Vala, 2005), com o apoio do programa informático Atlas.Ti. O sistema de categorias e subcategorias na análise relativa às atribuições da pobreza infantil foi desenvolvido a priori, com base na literatura já apresentada anteriormente (e.g., Bullock, 1999; Cozzarelli et al., 2001). Assim, num primeiro momento as unidades de texto (frases, parágrafos ou excertos de texto) foram selecionadas e sistematicamente codificadas de acordo com os tipos de atribuições presentes na literatura. Assim, as 191 unidades de texto identificadas no discurso das crianças foram agrupadas em 4 categorias, atribuições fatalistas, individualista, estruturalista e não sabe. Em relação à segunda e terceira questão, sobre a persistência da pobreza e infantil e soluções, o sistema de

2 A Acão Social Escolar é programa de apoio financeiro do Ministério da Educação às famílias com baixos rendimentos, determinado em função da situação dos alunos ou dos seus agregados familiares e em particular da respetiva condição socioeconómica. Os diferentes escalões de apoio, determinados pelo posicionamento do agregado familiar nos escalões de rendimento para atribuição de abono de família, correspondem o acesso a diferentes benefícios, diferentes níveis de benefício ou ainda diferentes graus de comparticipação pelos benefícios recebidos. 
categorias e subcategorias foi desenvolvido a posteriori, através da leitura, seleção e codificação sistemática de acordo com a ideia-chave que transmitiam. A análise da persistência da pobreza, resultou na codificação de 108 unidades de texto em 3 categorias: podem deixar de ser pobres, depende, não podem deixar de ser pobres. Por fim, em relação à dimensão das soluções para a pobreza infantil, as 155 unidades de texto foram agrupadas em 20 sub-categorias mutuamente exclusivas (ex: Ajuda de outras pessoas, Estudar), que foram posteriormente agrupadas em 2 categorias: criança pobre como agente de mudança e criança pobre não agente de mudança. A explicação e aprofundamento da análise de cada uma destas três dimensões é apresentada na secção de resultados.

Para garantir a fiabilidade e validade interna dos dados, as categorias/subcategorias foram construídas de forma exaustiva e exclusiva. 0 sistema de categorias foi sujeito a uma avaliação a partir da confiabilidade entre codificadores (Cohen, 1968), tendo sido pedido a um codificador externo à equipa de investigação a análise de 25\%-30\% da codificação de cada categoria. Os índices de confiabilidade (Cohen's K) para cada um do sistema de categorias associado a cada dimensão sugeriu elevada confiabilidade (atribuições da pobreza: $\kappa=0.96, p<0.001$; persistência da pobreza: $\kappa=0.82, p<0.001$; soluções para a pobreza infantil: $\kappa=0.97, p<0.001$ ). Foi também sujeito a acordo inter-juízes, o sistema de sub-categorias da dimensão soluções para a pobreza, nomeadamente a sua classificação em criança pobre agente de mudança e criança pobre não agente de mudança, sugerindo igualmente elevada confiabilidade $(\kappa=0.87, p$ $<0.001)$.

A análise dos dados permitiu a quantificação das dimensões em análise, tendo a análise dos dados sido posteriormente complementada com tratamentos estatísticos adequados aos objetivos do trabalho e apresentados na secção de resultados. Para além da presença e ausência de cada uma das categorias no discurso das crianças, foram criadas variáveis soma de todas as causas apresentadas pelo participante (independentemente do tipo de atribuição causal), uma variável com o numero de atribuições diferentes mencionadas pelo participante e o numero total de soluções apresentadas. Assim, os resultados que se apresentam em seguida visam descrever o fenómeno comparando os três grupos etários considerados (67 anos, 9-10 anos e 11-12 anos), tendo também em consideração o contexto socioeconómico da escola onde foram inquiridos (NSE contextual baixo e NSE contextual alto) e ainda o seu próprio NSE (NSE pessoal baixo e NSE pessoal alto).

\section{RESULTADOS}

Atribuições causais da pobreza

As respostas das crianças à pergunta sobre por que razão são as crianças pobres foram agrupadas nas categorias relativas às atribuições causais fatalistas (57\%; $n=61)$, estruturalistas (43\%; $n=46) \mathrm{e}$ individualistas (33\%; $n=35)$; foi criada, ainda, a categoria "não sabe" (14\%; $n=15)$, como se pode observar na Tabela 1. Nesta tabela, podem encontrar-se as frequências relativas e absolutas do número de crianças que mencionou cada atribuição causal analisada, o seu grupo etário e o NSE do contexto escolar. Nas colunas total, podem encontra-se o número de crianças de cada faixa etário, de cada NSE contextual, ou do total da amostra que referiu determinada atribuição.

Nas secções seguintes apresentamos exemplos de unidades de texto referentes a cada tipo de atribuição causal e analisamos a existência de diferenças na sua prevalência de acordo com o grupo etário e o nível socioeconómico da criança (NSEp), e ainda de acordo com o NSE do contexto escolar (NSEc). 
Tabela 1. Frequências absolutas e relativas do número de crianças que mencionou cada uma das atribuições causais da pobreza segundo os grupos etários e o NSE do contexto escolar

\begin{tabular}{llcccc}
\hline \multirow{2}{*}{ Atribuição causal } & NSE contexto escolar & $\mathbf{6 - 7}$ Anos & $\mathbf{9 - 1 0}$ Anos & $\mathbf{1 1 - 1 2}$ Anos & Total \\
\cline { 3 - 5 } & & $n(\%)$ & $n(\%)$ & $n(\%)$ & $n(\%)$ \\
\hline \multirow{3}{*}{ Individualista } & NSE Baixo & $7(39 \%)$ & $4(27 \%)$ & $6(38 \%)$ & $17(35 \%)$ \\
& NSE Alto & $4(24 \%)$ & $8(38 \%)$ & $6(30 \%)$ & $18(31 \%)$ \\
& Total & $11(31 \%)$ & $12(33 \%)$ & $12(33 \%)$ & $\underline{35(33 \%)}$ \\
\hline \multirow{5}{*}{ Estruturalista } & NSE Baixo & $2(11 \%)$ & $5(33 \%)$ & $12(75 \%)$ & $19(39 \%)$ \\
& NSE Alto & $2(12 \%)$ & $10(48 \%)$ & $15(75 \%)$ & $27(47 \%)$ \\
& Total & $4(11 \%)$ & $15(42 \%)$ & $27(75 \%)$ & $\underline{46(43 \%)}$ \\
\hline \multirow{3}{*}{ Fatalista } & NSE Baixo & $7(39 \%)$ & $6(40 \%)$ & $9(56 \%)$ & $22(45 \%)$ \\
& NSE Alto & $10(59 \%)$ & $16(76 \%)$ & $13(65 \%)$ & $39(67 \%)$ \\
& Total & $17(49 \%)$ & $22(61 \%)$ & $22(61 \%)$ & $\underline{61(57 \%)}$ \\
\hline \multirow{2}{*}{ Não sabe } & NSE Baixo & $5(28 \%)$ & $4(27 \%)$ & $1(6 \%)$ & $10(20 \%)$ \\
& NSE Alto & $3(18 \%)$ & $0(0 \%)$ & $2(10 \%)$ & $5(9 \%)$ \\
& Total & $8(23 \%)$ & $4(11 \%)$ & $3(8 \%)$ & $\underline{15(14 \%)}$ \\
\hline
\end{tabular}

Atribuições fatalistas. A maioria das crianças atribui a pobreza infantil a causas fatalistas ( $57 \% ; n=61)$, referindo acidentes ou acontecimentos da vida que conduziram as crianças à situação de pobreza, como exemplo, o facto de ter perdido a sua família ou mesmo ter sido abandonada pelos pais, ou porque alguém lhes roubou tudo o que tinham. Os exemplos seguintes, respetivamente, ilustram estas explicações.

“C: Ela é pobre porque perdeu a sua família." ( 6 anos, $\mathrm{NSE}_{\mathrm{c}}$ baixo, $\mathrm{NSE}_{\mathrm{p}}$ baixo).

"C: São pobres porque os pais a abandonaram, não queriam saber dela para nada e ficaram com todo o dinheiro que tinha. Depois ela ficou pobre, sem ninguém para a ajudar." (9 anos, NSE $E_{c}$ alto, $\mathrm{NSE}_{\mathrm{p}}$ alto)

"C: Eles (uns bandidos) roubaram-lhe tudo o que ele tinha, e agora ele está pobre." ( 9 anos, NSEc baixo, NSEp baixo)

Há ainda crianças que associam estes eventos inesperados a situações de doença, como ilustrado no exemplo seguinte:

"C: Porque os pais podem estar doentes. Podem ter problemas, doenças, ou outras coisas assim." (11 anos, NSEc baixo, NSEp alto).

Outras crianças referem, ainda, o destino como a principal causa para a situação de pobreza, como esta criança de 10 anos que considera que as crianças são pobres porque já nasceram assim:

"C: Se calhar os pais deles já tinham nascido pobres e na vida toda nunca conseguiram encontrar uma solução para não ficarem pobres." (10 anos, $\mathrm{NSE}_{c}$ alto, NSEp alto)

A atribuição causal fatalista não varia com a idade das crianças, $\chi^{2}(2)=1.511, p=.470$, ou com o NSE, $\chi^{2}(1)=0.821, p=.365$. Contudo, crianças que frequentam a escola com o NSE mais elevado referem mais causas fatalistas (67\%) do que as crianças da escola com um NSE inferior $(45 \%), \chi^{2}(1)=5.410, p=.02$.

Atribuições Estruturalistas. A explicação da pobreza causada por fatores sociais está igualmente presente no discurso de quase metade das crianças (43\%; $n=46)$. Estas causas podem estar relacionadas com a situação laboral dos pais destas crianças que, ou por estarem em situação de desemprego ou porque os seus trabalhos não são adequados. Podemos ver, respetivamente, nos exemplos abaixo, os discursos de três crianças que expressam estas possíveis causas. 
"C: Podiam, por exemplo, os pais terem empregos e depois serem despedidos e não ganhavam dinheiro. Ficavam desempregados e não conseguiam ganhar dinheiro para ter casa, pagar as despesas, comprar a comida, a roupa, essas coisas todas." (9 anos $\mathrm{NSE}_{\mathrm{c}}$ alto, $\mathrm{NSE}_{\mathrm{p}}$ alto)

"E: E o que é que achas que aconteceu para serem pobres?

C: Porque se calhar a vida está mal, não têm dinheiro porque se os pais tiverem sido despedidos não têm dinheiro para dar comida.

E: Foram despedidos?

C: Não têm trabalho, ou despedidos. Têm trabalhos só que não chegam para sustentar a família, não têm um trabalho adequado." (11 anos, $\mathrm{NSE}_{\mathrm{c}}$ baixo, $\mathrm{NSE}_{\mathrm{p}}$ baixo)

"C: A família, os pais podem trabalhar, mas podem não ganhar muito. E também por causa da crise também podem ter menos dinheiro." (12 anos, $\mathrm{NSE}_{\mathrm{c}}$ alto, $\mathrm{NSE}_{\mathrm{p}}$ alto)

As desigualdades existentes na sociedade foram também evocadas pelos participantes como possíveis causas para as crianças serem pobres.

"C: Cada vez vão tirando mais dinheiro às pessoas. As pessoas estão normais, depois os outros por exemplo aqueles que são mais ricos e isso vão tirando cada vez mais dinheiro aos que são pobres." ( 9 anos, $\mathrm{NSE}_{\mathrm{c}}$ baixo, $\mathrm{NSE}_{\mathrm{p}}$ baixo)

Em concordância com o hipotetizado, as crianças percebem que o locus da responsabilidade não é propriamente das crianças que estão nesta condição, mas sim da sua família que é a responsável por providenciar os seus cuidados a diferentes níveis. 0 discurso que se segue, embora enquadrado nas causas estruturalistas, ilustra esta ideia:

"Eu acho que é por causa disso, porque os pais têm de ajudar os filhos. Porque é a família que tem de ajudar os filhos." (11 anos, NSEc baixo, NSEp baixo)

Com a idade as crianças atribuem mais causas sociais à pobreza, $\chi^{2}(2)=29.302, p<.001$, sendo que entre os mais novos apenas $9 \%$ das crianças enunciaram este tipo de atribuições, entre as crianças com 910 anos 33\% fizeram-no e 59\% das crianças entre 11-12 anos referiram as causas estruturalistas como causas para a pobreza. A atribuição causal estruturalista não varia com o NSE pessoal das crianças, $\chi^{2}(1)=$ $1.260, p=.262$, ou com o NSE da escola, $\chi^{2}(1)=0.655, p=.418$.

Atribuições Individualistas. As causas individualistas são as menos mencionadas pelos participantes. Como causas individualistas, algumas crianças atribuem a responsabilidade às próprias crianças pela sua condição económica, como os casos seguintes demonstram.

“C: Ela veio de Espanha e ela não respeitou a mãe dela e ficou assim, agora a mãe dela não a ajuda. Porque ela às vezes batia na mãe dela." (12 anos, $\mathrm{NSE}_{\mathrm{c}}$ baixo, NSEp baixo)

"C: Se calhar porque sai de noite, a mãe avisava que não era para sair de noite, e depois a mãe ralhou mas como ele está sempre a sair de noite, tirou-o fora de casa." (10 anos, NSEc baixo, NSEp baixo)

Contudo, a maior parte dos participantes que atribuem este tipo de causas responsabilizam os pais das crianças pobres pela sua situação. Um exemplo dado é a má gestão das economias, como se ilustra no primeiro exemplo abaixo.

"E: E o que é que achas que aconteceu a essas crianças para serem pobres?

C: Acho que por exemplo podia ser uma pessoa que tinha dinheiro e gastou-o para nada. E depois, como não gostou, e acho que depois as outras pessoas como ela não tinham dinheiro e não podia dar dinheiro aos filhos. Não podia dar o que elas mereciam, não podia dar comida, não podia dar casa... pronto.

E: E ficaram pobres, porque gastaram o dinheiro mal gasto, é?

C: Sim.

E: Quando tu dizes (gastou-o) em nada, queres dizer o quê? 
C: Em nada por exemplo, ele podia comprar... por exemplo, ele tinha $10 €$, ele podia comprar uma televisão, ele podia comprar um comando, uma Play Station, e depois apercebia-se que essas coisas não serviam de nada. Mais valia ter comprado na comida, na casa." (9 anos, $\mathrm{NSE}_{c}$ alto, NSE alto)

Ainda centrando na responsabilidade dos pais, há participantes a referir que a falta de dinheiro e a situação de pobreza se deve a comportamentos de consumos ilícitos, como os exemplos seguidamente apresentados.

“C: A minha mãe já me disse que ele foi-se meter na droga e ficou pobre." (7 anos, NSE baixo, NSEp alto)

“C: Ou então também há pessoas que vão ao casino, jogam, perdem e depois ficam viciadas e continuam a jogar a jogar a jogar e depois perdem o dinheiro todo." ( 9 anos, $\mathrm{NSE}_{\mathrm{c}}$ baixo, NSE alto)

Outra causa referida é a incompetência da família ou dos pais das crianças pobres.

"E: E o que é que achas que aconteceu para serem pobres?

C: Os pais tinham dinheiro mas depois deviam ter dinheiro porque tinham trabalho. Mas trabalhavam muito mal e tiraram-no do seu emprego e depois já ficaram sem dinheiro.

E: Achas que é isso que acontece a todas as crianças que são pobres ou pode haver outras razões?

C: Acho que também podia ser que elas também... os pais trabalhavam mal no emprego e não ganhavam quase nada de dinheiro (mas sem perder o dinheiro)." ( 6 anos, NSEc baixo, NSEp alto)

Neste contexto, há ainda crianças que referem a necessidade de estudar para superar a situação de pobreza e apontam a falta de estudos como uma possível causa de caráter individual.

"C: Os pais não terem muito dinheiro porque ou não estudaram, ou foram trabalhar quando deviam era ter estudado." (11 anos, NSEc baixo, NSEp alto)

"E: Se for a situação que estás a falar eles têm culpa?

C: Sim, uma coisa que eu estou a pensar. Se sabem que têm de estudar, ter uma vida boa e precisam esforçar para sustentar se tiver uma família e depois faltarem às aulas e isso depois mais tarde não conseguem sustentar a família.

E: E achas que isso pode acontecer? Há pessoas que são pobres por causa disso, porque quando estavam na escola não estudaram o suficiente?

C: Sim, para terem uma vida boa, um trabalho adequado e bom... pronto." (11 anos, NSEc baixo, NSE baixo)

A atribuição causal individualista não varia com o NSE pessoal das crianças, $\chi^{2}(1)=0.566, p=.452$, ou com o NSE da escola, $\chi^{2}(1)=0.162, p=.688$. Estas causas também não se encontram associadas à idade das crianças, $\chi^{2}(2)=0.039, p=.981$.

Complexificação do processo atribucional. Um outro objetivo deste estudo era compreender em que medida é que as perceções sobre as causas da pobreza evoluem ao longo da idade. Neste caso, interessavanos compreender se as crianças ao longo da infância apresentavam uma complexificação do seu discurso no que diz respeito às causas da pobreza não só pela apresentação de um número mais elevado de causas explicativas da existência da pobreza infantil, mas também pela diversificação do tipo de atribuições causais apresentadas, isto é, pela coocorrência de diferentes atribuições causais. Na Tabela 2, podem lerse em média, quantas explicações é que as crianças mencionaram segundo o grupo etário e o NSE do contexto escolar.

Assim, para compreender o efeito da idade e do contexto socioeconómico das crianças no número de explicações causais da pobreza, foi realizada uma análise de variância com dois fatores. Os resultados, apresentados na Tabela 2, revelam que, em geral, as crianças enunciam em média 1.64 causas para explicar a pobreza infantil $(D P=1.08)$. A ANOVA revelou um efeito principal da idade que indica que o número de explicações aumenta com a idade, $F(2,99)=12.210, p<.001, \eta^{2}=.18$. Os resultados revelam, ainda, um efeito principal do NSE da escola - as crianças da escola com NSE mais elevado referem um número superior de explicações em comparação com as crianças da escola com NSE inferior, $F(1,99)=5.194, p=$ $.026, \eta^{2}=.04$. Não foi encontrado efeito de interação significativo, $F(2,99)=2.670, p=.074, \eta^{2}=.04$. 
Tabela 2. Medidas descritivas (média e desvio padrão) do número de explicações causais da pobreza em função do grupo etário e do NSE do contexto escolar

\begin{tabular}{lcccc}
\hline \multirow{2}{*}{ NSE contexto escolar } & $\mathbf{6 - 7}$ Anos & $\mathbf{9 - 1 0}$ Anos & $\mathbf{1 1 - 1 2}$ Anos & Total \\
\cline { 2 - 5 } & $M(D P)$ & $M(D P)$ & $M(D P)$ & $M(D P)$ \\
\hline NSE Baixo & $1.00(0.79)$ & $1.13(0.92)$ & $2.00(1.10)$ & $1.38(1.02)$ \\
NSE Alto & $1.00(0.63)$ & $2.14(0.96)$ & $2.25(1.12)$ & $1.86(1.08)$ \\
Total & $1.00(0.71)$ & $1.72(1.06)$ & $2.14(1.1)$ & $1.64(1.08)$ \\
\hline
\end{tabular}

Os resultados evidenciam ainda que estas atribuições que as crianças fazem não são exclusivas. No seu discurso, as crianças indicam causas que se podem incluir em diferentes tipos de atribuições causais da pobreza. Assim, para além do número de causas que as crianças apresentam no seu discurso, a complexificação das perspetivas atribucionais traduz-se, também, nesta diversidade de tipos de atribuições que cada criança refere. 0 exemplo seguinte traduz justamente isso, na medida em que a criança, com 11 anos, refere que a situação económica das crianças pobres pode resultar de causas sociais, como a falta de emprego, mas também de uma fatalidade na sua vida, como o abandono pelos pais:

"Ou os pais não têm dinheiro suficiente ou não têm emprego. Ou então foram abandonadas pelos pais e ficaram na rua." (11 anos, $\mathrm{NSE}_{\mathrm{c}}$ alto, NSE alto).

Os resultados revelam que com a idade as crianças mencionam cada vez mais tipos diferentes de atribuições causais da pobreza. Tal como se pode ver na Tabela 3, 28\% das crianças com 6-7 anos mencionam dois tipos de atribuições, enquanto $50 \%$ das crianças com 9-10 anos e 73\% das crianças com 11-12 anos mencionam dois ou mais tipos de atribuições em simultâneo ao longo do seu discurso, $\chi^{2}(2)=$ $13.538, p=.009$.

Tabela 3. Frequências absolutas e relativas do número de atribuições causais segundo o grupo etária

\begin{tabular}{lccc}
\hline Diversificação de atribuições & $\mathbf{6 - 7}$ anos & $\mathbf{9 - 1 0}$ anos & $\mathbf{1 1 - 1 2}$ anos \\
\cline { 2 - 4 } causais & $n(\%)$ & $n(\%)$ & $n(\%)$ \\
\hline Um tipo de atribuição & $18(72 \%)$ & $16(50 \%)$ & $9(27 \%)$ \\
Dois tipos de atribuições & $7(28 \%)$ & $15(47 \%)$ & $20(61 \%)$ \\
Três tipos de atribuições & $0(0 \%)$ & $1(3 \%)$ & $4(12 \%)$ \\
\hline
\end{tabular}

Analisando especificamente quais as coocorrências mais frequentes no discurso das crianças, a referência a causas fatalistas e causas estruturalistas são aquelas que surgem mais vezes mencionadas pela mesma criança $(21 \%, n=23)$, seguida das causas individualistas em coocorrência com as fatalistas $(10 \%$, $n=11$ ) e por fim as causas estruturalistas e as individualistas são aquelas que surgem menos vezes mencionadas pelas mesmas crianças $(7 \%, n=8)$.

\section{Persistência da pobreza e soluções para sair da pobreza}

Para além das causas da pobreza, os participantes foram questionados sobre a sua crença relativamente à persistência da situação de pobreza das crianças pobres. Para tal, foi-lhes colocada a seguinte questão: “Achas que as crianças pobres vão ser pobres para sempre ou podem deixar de ser pobres?". A quase totalidade das crianças considera que as crianças podem deixar de ser pobres - 91\% considera que a pobreza infantil pode ter um fim e que, reunidas determinadas condições, as crianças pobres podem deixar de o ser. Apenas 5\% das crianças refere que 'depende' e 4\% que considera que não será possível às crianças pobres deixarem de o ser.

Os participantes que referiram que as crianças pobres podem deixar de o ser, ou que isso depende, foram questionadas sobre o que teria que acontecer para esse efeito. As suas respostas foram agrupadas em 20 subcategorias e posteriormente agrupadas em 2 categorias que contemplam as respostas que colocam a criança pobre como agente da sua saída da pobreza ou não. Na Tabela 4, apresentam-se as frequências relativas para cada uma das categorias e para as quatro subcategorias cujas observações foram superiores a 10 unidades de texto, isto é, que reuniram maior número de respostas. Como se pode ver, as soluções apresentadas pelas crianças dividem-se quase igualmente entre aquelas que colocam a criança como agente de pobreza $(n=48,45 \%)$ e as que colocam esta agência externa à criança $(n=68 ; 64 \%)$. 
Tabela 4. Frequências absolutas e relativas para as soluções das causas da pobreza

\begin{tabular}{llc}
\hline Soluções & $\boldsymbol{n}$ & \% \\
\hline Criança pobre não agente & 68 & $64 \%$ \\
Alguém ajuda: dar dinheiro & 42 & $40 \%$ \\
Alguém ajuda: adotar/acolher & 18 & $17 \%$ \\
Criança pobre agente & 48 & $45 \%$ \\
Encontrar emprego & 27 & $26 \%$ \\
Estudar & 19 & $18 \%$ \\
\hline
\end{tabular}

Em alguns casos, estas condições foram muitas vezes apresentadas espontaneamente, como condições para as crianças pobres poderem deixar de ser pobres, como se pode ver no exemplo abaixo, de uma criança de 10 anos:

"E: E achas que ele/a vai ser para sempre pobre ou pode deixar de ser pobre?

C: Pode deixar de ser pobre.

E: Porquê?

C: Porque pode haver alguma pessoa que seja boa, muito boa, e pode querer levá-la para sua casa e dar-lhe coisas e assim pode passar a ser mãe dela, ou pai dela.

E: Então, o que achas que tem de acontecer para eles deixarem de ser pobres?

C: Ela tem que não se esconder muito para ver se alguém a quer levar, mas também não pode ir com toda a gente tem de ver se essa pessoa é meiga, mas também não é ninguém que faça muitos carinhos, pode ser outra coisa." (10 anos, NSEc baixo, NSEp baixo)

A forma mais mencionada como solução para a criança superar a sua situação de pobreza está, porém, relacionada com a ajuda de outras pessoas, neste caso através da sua ajuda dando dinheiro, comida, roupa, entre outros bens necessários.

"Se calhar vão deixar de ser pobres porque as pessoas vão lhe dando dinheiro e à medida que eles vão juntando e depois vão comprar comida e vão comprar coisas que necessitem." (9 anos, NSEc alto, NSEp alto)

Do mesmo modo, 16\% das crianças mencionam ainda que uma outra possibilidade pode passar pela adoção da criança que é pobre por uma família que a possa cuidar e dar-lhe aquilo que necessita. Ambas as possibilidades entendem a criança como alvo de ajuda, sem contemplarem a situação de que a criança seja capaz de, por si só, superar a sua situação de pobreza.

"E: E o que é que tem de acontecer para deixarem de ser pobres?

C: Adultos podiam passar por lá, verem as crianças a sofrer, pobres, todas sujas com as roupas rasgadas, e terem pena, ajudarem a criança, levarem-na para casa, terem pena e tratarem dele como se fosse filho e darem-lhes roupas melhores." ( 9 anos, $\mathrm{NSE}_{c}$ alto, NSE alto)

Por outro lado, um quarto dos participantes refere que as crianças pobres podem arranjar um emprego quando crescerem, arranjando dinheiro para se sustentarem e à sua família e quase um quinto menciona a importância de estudar para que a criança possa sair da situação de pobreza.

"E: E o que achas que pode acontecer?

C: Quando eles passarem a ser grandes já não são pobres.

E: Porquê? 0 que aconteceu?

C: Ficam com dinheiro. Vão para um trabalho." (6 anos, NSEc baixo, NSE

"Há vários exemplos de pessoas que eram pobres, estudaram, estudaram, conseguiram ter muito boas notas e depois, conseguiram fazer a faculdade." (12 anos, $\mathrm{NSE}_{\mathrm{c}}$ alto, $\mathrm{NSE}_{\mathrm{p}}$ alto)

A perceção de que a criança pobre deve ser agente de mudança aumenta com a idade, $\chi^{2}(2)=7.606$, $p=.022$. Entre as crianças mais novas 32\% $(n=11)$ apresenta soluções em que a criança pobre é vista como agente de mudança e entre as mais velhas este tipo de soluções é apresentado por $65 \%$ das crianças $(n=$ 
22). 0 NSE contextual, $\chi^{2}(1)=1.709, p=.191$, e pessoal, $\chi^{2}(1)=0.624, p=.429$, não se mostram relevantes nas soluções internas à criança pobre (agente).

No que diz respeito à solução em que a criança pobre não é agente de mudança, não se encontraram diferenças em relação aos vários grupos etários, $\chi^{2}(2)=3.996, p=.136$. Contudo, em relação ao NSE, a solução externa à criança pobre (não agente) varia com o NSE contextual, $\chi^{2}(1)=5.633, p=.018$, sendo que entre as crianças que frequentam a escola de elevado NSE 75\% $(n=43)$ apresenta este tipo de soluções, enquanto na escola de baixo estatuto este tipo de soluções externas à criança são apresentados por $53 \%$ ( $n$ $=25)$. A variação existente nestas soluções externas em relação ao NSE pessoal é marginal, $\chi^{2}(1)=3.258, p$ $=.071$, sendo que as crianças de NSE elevado $(75 \%, n=48)$ mencionam mais estas causas do que as de NSE baixo $(54 \%, n=20)$.

Por último, analisamos o papel das atribuições causais ao longo da infância no desenvolvimento das perceções das crianças sobre as soluções para saída da pobreza infantil. Assim, testámos o papel mediador das atribuições causais da pobreza na relação entre a idade e a perceção de que a criança pobre pode ser, ou não, agente de mudança na resolução da sua situação de pobreza. Foram conduzidas separadamente seis mediações probit, com os três tipos de atribuição causal como variável mediadora e como variáveis dependentes a apresentação de soluções para a saída da pobreza em que a criança pobre é agente de mudança (dimensão "Criança pobre agente" presente/ausente no discurso) e não é agente de mudança (dimensão "Criança pobre não agente" presente/ausente no discurso). A escolha desta análise reside no facto de as variáveis mediadoras e dependentes serem dicotómicas. Estas análises foram conduzidas em Mplus versão 7.31 (Muthen e Muthen, 2012) com o estimador dos mínimos quadrados ponderados com média e variância ajustadas (WLSMV), apropriado para variáveis mediadoras e dependentes categoriais. Foi utilizado o método não paramétrico de bootstrap com 10000 amostras para obter os intervalos de confiança a 95\% dos efeitos indiretos.

Entre as seis análises de mediação efetuadas, apenas se mostrou estatisticamente significativa a mediação da relação entre a idade e a perceção de soluções com a criança pobre como agente via atribuições estruturalistas da pobreza ${ }^{3}$. Assim sendo, apenas esta mediação é apresentada aqui. 0 modelo de mediação testado apresenta uma melhoria no ajustamento em relação ao modelo nulo, $\chi^{2}(2)=11.315, p=.0044$.

Num primeiro passo, e em linha com os resultados anteriores, verifica-se que com a idade aumenta a probabilidade de as crianças apresentarem soluções que passam pela ação da própria criança pobre, $B=$ $0.133, E P=0.061,95 \%$ CI [0.019, 0.255], $p=.030$ (Figura 1). Num segundo momento, verificamos que a idade é igualmente preditora das atribuições causais da pobreza associadas a fatores sociais, $B=0.296, E P$ $=0.072,95 \% \mathrm{CI}[0.167,0.448], p<.001$. Concretamente, com a idade as crianças tendem a apresentar mais no seu discurso atribuições causais estruturalistas. Por último, uma terceira regressão incluindo a idade e a atribuição estruturalista como preditoras das soluções da pobreza que apontam as crianças pobres como agentes de mudança, mostra que a apenas as atribuições se relacionam significativamente com as soluções, $B=0.369, E P=0.154,95 \% \mathrm{CI}[0.042,0.644], p=.017$, e a idade deixa de predizer a soluções, $B=0.023, E P$ $=0.080,95 \%$ CI $[-0.136,0.178], p=.567$. O efeito indireto é significativo, $B=0.110, E P=0.056,95 \%$ BootCI $[0.017,0.238]$. Estes resultados são consistentes com um efeito de mediação total.

Em suma, estes resultados indicam que com a idade aumenta a perceção de soluções que visam as crianças pobres como agentes de mudança na sua situação de pobreza uma vez que com a idade também aumenta a identificação de atribuições causais estruturalistas à pobreza infantil.

\footnotetext{
3 Efeitos indiretos não significativos em todas as mediações entre idade e a perceção de soluções para saída da pobreza em que a criança pobre não é agente da mudança: mediador 'atribuição estruturalista', $B=-0.010, E P=0.058,95 \%$ Boot IC $[-0.126,0.105]$, mediador 'atribuição individual', $B=-0.002$, $E P=0.011,95 \%$ Boot IC $[-0.038,0.013]$, e mediador 'atribuição fatalista', $B=0.023, E P=0.024,95 \%$ Boot IC [-0.010, 0.089]. Efeitos indiretos não significativos nas mediações entre idade e a perceção de soluções para saída da pobreza em que a criança pobre é agente da mudança: mediador 'atribuição individualista', $B=0.004, E P=0.015,95 \%$ Boot IC $[-0.014,0.058]$, e mediador 'atribuição fatalista', $B=-0.002, E P=0.015,95 \%$ Boot IC [$0.045,0.022]$.

${ }^{4}$ Conduzimos um teste robusto de diferença do qui-quadrado do modelo usando a função Mplus DIFFTEST de modo a perceber se o modelo proposto corresponde a uma melhoria de ajustamento (aplicada para testar modelos nested com o estimador WLSMV). Esta função do Mplus compara o ajustamento do modelo nulo ( $\mathrm{H}_{0}$ : Modelo sem efeitos diretos) com um modelo alternativo $\left(\mathrm{H}_{0}\right.$ : Modelos com todos os efeitos diretos presentes), e testa a hipótese de que a inclusão das variáveis 'atribuição causal estruturalista' e 'idade' enquanto preditoras das soluções para a pobreza infantil que veem a criança como agente da mudança melhora o ajustamento do modelo.
} 


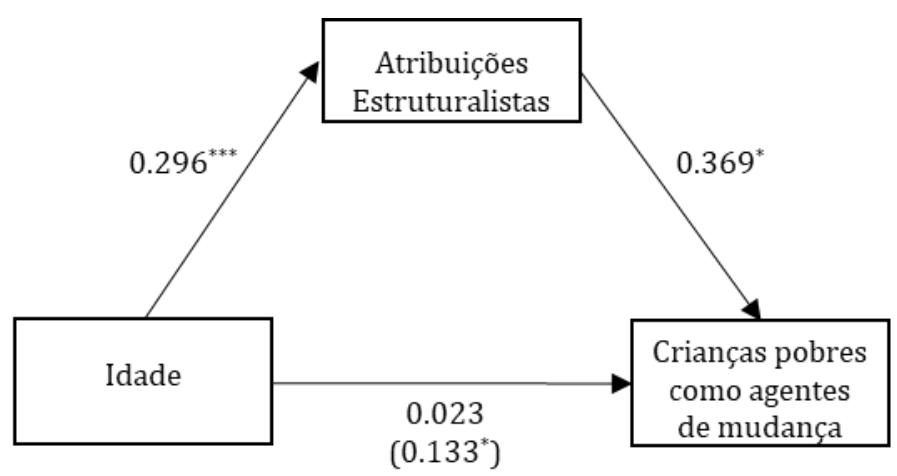

Figura 1. Modelo de análise das atribuições causais estruturalistas como mediadores da relação entre idade das crianças e a apresentação de soluções em que a criança pobre é agente da resolução da sua situação de pobreza. As setas indicam a presença de efeito indiretos significativos. Os coeficientes beta entre parênteses referem-se ao efeito total da idade nas soluções.

$$
{ }^{*} \mathrm{p}<0.05,{ }^{* *} \mathrm{p}<0.01,{ }^{* * *} \mathrm{p}<0.001 \text {. }
$$

Tabela 5. Resultados de regressão probit para o modelo de mediação.

\begin{tabular}{lcccc}
\hline & \multicolumn{2}{c}{$\begin{array}{c}\text { Atribuições causais } \\
\text { estruturalistas (1) }\end{array}$} & \multicolumn{2}{c}{$\begin{array}{c}\text { Criança pobre como } \\
\text { agente de mudança (2) }\end{array}$} \\
\cline { 2 - 5 } & $\boldsymbol{B}$ & $\boldsymbol{E P}$ & $\boldsymbol{B}$ & $\boldsymbol{E}$ \\
\hline Efeito total & & & $-1.304^{*}$ & 0.575 \\
Constante & & & $0.133^{*}$ & 0.061 \\
Idade & & & \\
Efeito direto & & & $-1.306^{*}$ & 0,575 \\
Constante & $-2.938^{* * *}$ & 0.698 & 0.023 & 0.080 \\
Idade & $0.296^{* * *}$ & 0.072 & $0.369^{*}$ & 0.154 \\
Atribuições causais estruturalistas & & & & \\
Efeito indireto & & & & \\
$\quad$ Coef. & EP & $95 \%$ Bootstrap IC & & \\
$\quad 0.110$ & 0.056 & 0.017 & 0.238 & \\
\hline
\end{tabular}

Nota. ${ }^{* * *} p<0.001{ }^{* *} p<0.01,{ }^{*} p<0.05$

(1) Presença de atribuições causais da pobreza no discurso - categoria de referência

(2) Apresentação de soluções em que criança pobre é agente de mudança - categoria de referência

\section{DISCUSSÃo}

Este estudo teve como objetivo descrever o desenvolvimento e a relação entre as atribuições causais da pobreza infantil e a perceção das soluções para este problema social em crianças com idades entre os 6 e os 12 anos, que se encontravam a frequentar duas escolas com um nível socioeconómico maioritariamente baixo ou elevado.

Os resultados permitem concluir que, nas idades em análise, as crianças são capazes de avançar explicações para a pobreza infantil, e que estas explicações estão em linha com aquelas que têm sido identificadas na literatura com adultos. Assim, as atribuições referidas pelas crianças podem ser classificadas como estruturalistas, fatalistas ou individuais.

Em linha com a literatura (Leahy, 1981; Rholes \& Ruble, 1984) e as nossas hipóteses, as atribuições externas (estruturalistas e fatalistas) são as mais prevalentes nas explicações das crianças. Contudo, ao contrário de outros estudos neste domínio, onde as causas sociais foram as mais mencionadas (Amar et al., 2015; Chafel \& Neitzel, 2005; Hakorvita \& Kallio, 2016), no presente estudo as atribuições mais prevalentes foram as fatalistas. Nestas, as crianças pobres são vistas como vítimas do destino, seja porque sofreram acidentes que as privaram de condições económicas mais favoráveis, seja porque nasceram numa família economicamente desfavorecida, ou ainda porque foram abandonadas pelos pais. Este resultado poderia levar-nos a pensar que esta explicação seria frequente na cultura portuguesa e que, por via da socialização, estaria mais presente no discurso das crianças. Contudo, estudos com adultos mostram que Portugal, a par com países como o Hungria, Lituânia ou Polónia, entre outros, atribuem à pobreza causas estruturalistas (Costa \& Dias, 2015). Alternativamente, consideramos que este resultado pode ser explicado pelo facto de 
o estudo ter focado especificamente as explicações da pobreza infantil (e não a pobreza em adultos). Dado que os alvos são crianças, podem ter sido ativadas as crenças quanto à autonomia e responsabilidade limitada das crianças para assegurarem a sua subsistência e, consequentemente, evocando a sua desfortuna.

Embora a prevalência das atribuições fatalistas não varie com a idade, os resultados mostraram que são mais prevalentes nas escolas com elevado NSE. Considerando o papel da socialização e da experiência direta na aprendizagem das atribuições causais (Chafel \& Neitzel, 2005), é possível que em meios particularmente afluentes as oportunidades de aprendizagem sobre os fatores associados às variações socioeconómicas, e à pobreza em particular, sejam mais limitadas, por contraste com os contextos onde a instabilidade laboral e as privações económicas têm uma incidência elevada, resultando numa maior evocação de explicações fatalistas.

A perceção de que as causas da pobreza são alheias ao indivíduo e à sociedade apresenta a criança pobre como vítima do seu destino, uma criança com pouca sorte. Apesar de não serem conhecidos estudos que relacionem as atribuição de causas fatalistas com a manifestação de atitudes mais negativas face aos pobres, em vários estudos, Olson e colegas $(2006$; 2008) mostram que as crianças, ao longo da infância e independentemente da cultura, preferem aqueles que experienciam a sorte àqueles que têm azar (Olson et al., , 2006; 2008). Ainda, as crianças tendem a julgar os alvos "azarados" como mais propensos a comportarem-se negativamente. Estas evidências sugerem que a explicação da pobreza infantil associada ao destino e à "má sorte" pode reforçar a marginalização das crianças pobres pelos seus pares.

As atribuições externas estruturalistas (e.g., ao desemprego, crise económica, governo vigente) são as segundas mais prevalentes no nosso estudo, o que está em linha com estudos anteriores que analisaram as perceções de crianças e adolescentes sobre as razões da pobreza em geral (Hakorvita \& Kallio, 2015, Amar et al., 2015). Tal como admitimos nas hipóteses, verifica-se que a prevalência destas atribuições aumenta com a idade, e é aquela com maior expressão aos 11-12 anos. Este resultado vem demonstrar que, com a idade, e porventura com a consequência de um efeito combinado do desenvolvimento sociocognitivo e da socialização (Abrams et al., 2009), as crianças tendem a alargar a sua visão do fenómeno da pobreza, concretamente quanto ao papel de fatores externos determinados, em lugar daqueles externos de natureza aleatória / fatalista.

As atribuições individualistas são aquelas menos referidas no discurso das crianças, um resultado que está de acordo com a literatura (Hakorvita \& Kallio, 2016). Contudo, e como evidenciado por Hussak e Cimpian (2015), no nosso estudo as crianças com 6-7 anos também foram capazes de atribuir a pobreza a causas internas, especificamente às crianças pobres, sem que se tenha verificado variação com a idade. Embora este resultado não seja qualificado pelo NSE da família das crianças ou da escola, o facto de algumas crianças mais novas reconhecerem o papel de causas internas poderá ser explicado pela circunstância de as crianças em Portugal estarem, em geral, bastante expostas ao fenómeno da pobreza, e neste sentido, também às explicações individualistas que circulam na sociedade. Quanto às crianças mais velhas, apesar de estarem mais capacitadas, do ponto de vista do desenvolvimento sociocognitivo, para o reconhecimento das atribuições individualistas (Rholes \& Ruble, 1984), concomitantemente também estarão mais sensíveis às normas sociais que condenam a expressão de preconceito e discriminação (França \& Monteiro, 2013; Monteiro et al., 2009; Rodrigues et al., 2012; 2016) e que poderão inibir o seu reconhecimento explícito. Finalmente, e como referido acima, admitimos que a baixa prevalência das explicações individualistas traduza o conhecimento de que as crianças se encontram dependentes de terceiros, e que as crianças pobres, em particular, não têm responsabilidade pelas suas condições sociais e económicas. De facto, embora uma minoria de crianças tenha referido que os comportamentos da criança pobre a conduziram à situação de pobreza (e.g., saiu de casa; portou-se mal), a maioria responsabiliza os pais dessa criança.

De acordo com pesquisas anteriores com crianças e adultos (Hakorvita \& Kallio, 2016; Kreidl, 2000), o presente estudo demonstrou que em diferentes idades as crianças são capazes de mobilizar, simultaneamente, atribuições de diferentes tipos, e ainda que esta complexificação, a par da multiplicação dos conteúdos atribucionais, ganha expressão com a idade. Provavelmente este resultado é explicado, quer pela capacidade acrescida de as crianças mais velhas integrarem informação complementar, e até contraditória (França \& Monteiro, 2013; Monteiro et al., 2009), quer pela sua exposição a uma crescente variedade de perspetivas sobre o fenómeno da pobreza no contexto dos processos normais de socialização.

O presente estudo prosseguiu um segundo objetivo, nomeadamente o de verificar se as crianças consideram que a pobreza infantil constitui um problema com solução, e admitindo as crianças que sim, quais seriam as eventuais soluções. Praticamente todas as crianças entrevistadas consideraram que as crianças pobres não vão ser pobres para sempre, e em linha com os resultados que mostram uma maior prevalência das atribuições externas (fatalistas e estruturalistas), verificou-se que a maioria das crianças identifica como soluções para a pobreza infantil ações externas à criança que, portanto, não a responsabilizam pela resolução da situação de pobreza. 
Contudo, não se confirmou a nossa hipótese de que as soluções externas à criança estariam associadas às atribuições externas, e que as soluções com a criança como agente da mudança estariam associadas às atribuições individualistas. Concretamente, os resultados mostraram que as soluções para a pobreza infantil que exigem a ação por parte das crianças pobres se encontram associadas às atribuições estruturalistas, e que esta associação constitui o caminho que explica o aumento da prevalência deste tipo de soluções com a idade. Por outras palavras, as soluções cujo agente da mudança é a própria criança pobre aumentam com a idade uma vez que com a idade também aumentam as explicações que sinalizam o papel de fatores externos sócio-estruturais. Na nossa perspetiva este resultado não previsto e paradoxal pode ter duas explicações.

Por um lado, esta ligação pode estar relacionada com a perspetiva de que, considerarem a criança agente de mudança significa ao mesmo tempo considerarem-na capaz para, sozinha, ultrapassar as adversidades e poder um dia ter outras condições de vida. Admitimos, portanto, a hipótese de que ao contrário dos adultos pobres - que são estereotipados como preguiçosos ou incompetentes (Cozzarelli et al., 2001; Enesco \& Navarro, 2003) - as crianças pobres possam ser percebidas como resilientes e competentes, e tanto mais quanto mais se entenda que a estrutura social é, á partida, responsável pelas condições económicas de pobreza. Esta perspetiva é compatível com a visão de que as crianças, compreendem que o caminho para a saída da pobreza passa pela mobilidade social do indíviduo, assegurada por ex. pelos estudos e por garantir um emprego melhor.

Por outro lado, ao referir estas soluções as crianças não concebem a mudança social enquanto caminho para a redução da pobreza, o que leva à consideração de que este resultado possa traduzir um fenómeno de legitimação do sistema (Olson et al., 2008), que radica na forma como as desigualdades sociais são enquadradas pelas políticas económicas e sociais vigentes. As crenças de que os sistemas sociais são justos estão presentes desde os 4-6 anos de idade (Hussak \& Cimpian, 2015), e incorporam a noção de que o esforço individual é recompensado; neste caso, que se a criança se esforçar conseguirá (no futuro) ultrapassar e resolver a sua condição social desfavorável eminentemente injusta, repondo, desse modo, a justiça do sistema. Ainda, o desenvolvimento desta perspetiva de que a solução para os problemas estruturais se realiza na esfera da ação individual pode reduzir o apoio futuro a políticas públicas que visam a redução estrutural das desigualdades sociais.

A ligação entre as atribuições causais e as perceções das soluções para a pobreza infantil devem merecer a atenção de estudos futuros. Mais concretamente, e apoiando-nos nos estudos sobre o desenvolvimento das atitudes proto-políticas (Hussak \& Cimpian, 2015, 2018), será importante averiguar de que modo as atribuições causais da pobreza infantil na infância se ligam às crenças sobre a justiça dos sistemas e da adequação das diferentes políticas sociais. Por outro lado, poderá ser importante explorar de que modo estas atribuições se relacionam com os traços estereotípicos das crianças pobres e, atendendo à relação conhecida entre as crenças essencialistas e a expressão de comportamentos negativos em contexto intergrupal (Rhodes et al., 2018), analisar a relação entre as atribuições causais e as atitudes e os comportamentos face às crianças pobres, por exemplo, em termos de distribuição de recursos. Estudos futuros devem considerar estudar estas perceções de forma mais extensiva, em estudos experimentais, de forma a testar concretamente a causalidade destas relações. Para além disso, o papel do estatuto socioeconómico das crianças na forma como analisam este fenómeno deverá ser aprofundado, sendo fundamental a inclusão de uma medida mais precisa de NSE, possivelmente agregando várias informações sociodemográficas como a profissão dos pais, rendimentos, entre outros.

Em conclusão, a investigação com crianças em torno das atribuições causais tem um papel fundamental para a compreensão do modo como as crianças explicam o mundo que as rodeia, e quais as suas perceções sobre os fenómenos sociais. Neste estudo, dando-lhes voz, foi possível conhecermos as suas explicações sobre o fenómeno da pobreza infantil, bem como as soluções que já perspetivam para a pobreza infantil. Ao contrário dos estudos até agora desenvolvidos, a reflexão das crianças sobre os seus pares que vivem em situação de pobreza, ou seja o enfoque na pobreza infantil em vez de focar na pobreza em geral, é fundamental para um entendimento mais aprofundado dos comportamentos de inclusão e exclusão de crianças pobres na infância. Há evidência de que em escolas mais heterógeneas, as crianças de NSE mais baixo se sentem discriminadas devido ao seu estatuto económico (Hooper et al., 2007). Para além disso, a literatura sobre o modo como a comunidade escolar trabalha estes assuntos na sala de aula (e.g. White et al., 2013) evidencia que, ao contrário de outras categorias sociais (e.g., género ou etnia), a classe social constitui, ainda, um tema tabu, de difícil abordagem pelos professores. Os resultados deste estudo podem, assim, apoiar e informar projetos e ações que visem explorar e aprofundar estas temáticas com as crianças, tornando-as parte ativa no debate e na intervenção futura sobre as desigualdades sociais e a pobreza. 


\section{REFERÊNCIAS}

Abrams, D., Rutland, A., Pelletier, J., \& Ferrell, J. M. (2009). Children's group nous: Understanding and applying peer exclusion within and between groups. Child Development, 80(1), 224-243. http://dx.doi.org/10.1111/j.1467-8624.2008.01256.x

Alvarez, J. M., Ruble, D. N., \& Bolger, N. (2001). Trait understanding or evaluative reasoning? An analysis of children's behavioral predictions. Child Development, 72(5), 1409-1425. http://dx.doi.org/10.1111/1467-8624.00356

Amar Amar, J., Llanos, R., Martinez-González, M., Monroy Agamez, E., Cortés, O. e Crespo, F. (2015). Beliefs about poverty related to social categorization in childhood. Suma Psicológica, 22(1), 9-17. http://dx.doi.org/10.1016/j.sumpsi.2015.05.002

Bradshaw, D., Jay, S., McNamara, N., Stevenson, C., \& Muldoon, O. T. (2016). Perceived discrimination amongst young people in socio-economically disadvantaged communities: Parental support and community identity buffer (some) negative impacts of stigma. British Journal of Developmental Psychology, 34(2), 153-168. http://dx.doi.org/10.1111/bjdp.12120

Bullock, H.E. (1999). Attributions for poverty: A comparison of middle-class and welfare recipient attitudes. Journal of Applied social Psychology, 29(10), 2059-2082. http://dx.doi.org/10.1111/j.15591816.1999.tb02295.x

Carlo, G. (2006). Care-based and altruistically based morality. In M. Killen \& J. Smetana (Eds.), Handbook of moral development (pp. 551-580). Routledge Press.

Chafel, J. A., \& Neitzel, C. (2005). Young children's ideas about the nature, causes, justification, and alleviation of poverty. Early Childhood Research Quarterly, 20(4), 433-450. http://dx.doi.org/10.1016/j.ecresq.2005.10.004

Cimpian, A., \& Steinberg, O. D. (2014). The inherence heuristic across development: Systematic differences between children's and adults' explanations for everyday facts. Cognitive psychology, 75, 130-154. http://dx.doi.org/10.1016/j.cogpsych.2014.09.001

Costa, L. P., \& Dias, J. G. (2015). What do Europeans believe to be the causes of poverty? A multilevel analysis of heterogeneity within and between countries. Social Indicators Research, 122(1), 1-20. http://dx.doi.org/10.1007/s11205-014-0672-0

Correia, I., Vala, J., Aguiar, Patrícia (2007). Victim's innocence, social categorization and the threat to the belief in a just world. Journal of Experimental Social Psychology, 1(43), 31-38. http://dx.doi.org/10.1016/j.jesp.2005.12.010

Cozzarelli, C., Wilkinson, A. \& Tagler,M. (2001). Attitudes toward the poor and attributions for poverty. Journal of Social Issues.,57(2), 207-227. http://dx.doi.org/10.1111/0022-4537.00209

Crowley, A. and Vulliamy, C. (2007). Listen up! Children and young people talk: About poverty. Save the Children Wales.

Enesco, I., \& Navarro, A. (2003). The development of the conception of socioeconomic mobility in children from Mexico and Spain. The Journal of Genetic Psychology, 164(3), 293-317. http://dx.doi.org/10.1080/00221320309597985

European Union Agency for Fundamental Rights (FRA) (2018). A persisting concern: anti-Gypsyism as a barrier to Roma inclusion. Publications Office.

Feddes, A. R., Monteiro, M. and Justo, M. G. (2014), Subjective social status and intergroup attitudes among ethnic majority and minority children in Portugal. British Journal of Development Psychology, 32, 125140. http://dx.doi.org/10.1111/bjdp.12025

França, D. X. D., \& Monteiro, M. B. (2002). Identidade racial e preferência em crianças brasileiras de cinco a dez anos. Psicologia, 16(2), 293-323. http://dx.doi.org/10.17575/rpsicol.v16i2.482

França, D. X. e Monteiro, M. B. (2013). Social norms and the expression of prejudice: The development of aversive racism in childhood. European Journal of Social Psychology, 43, 263-271. http://dx.doi.org/10.1002/ejsp.1965

Hakovirta, M. \& Kallio, J. (2016). Children's Perceptions of Poverty. Child Indicators Research, 9, 317-334. http://dx.doi.org/10.1007/s12187-015-9315-5

Higgins, E. T., \& Bryant, S. L. (1982). Consensus information and fundamental attribution error: The role of development and in-group versus out-group knowledge.Journal of Personality and Social Psychology, 43(5), 889. http://dx.doi.org/10.1037/0022-3514.43.5.889

Hooper, C.A., Gorin, S., Cabral, C. and Dyson, C. (2007). Living with hardship 24/7: The diverse experiences of families in poverty in England. NSPCC/The Frank Buttle Trust.

Hussak, L. J., \& Cimpian, A. (2015). An early-emerging explanatory heuristic promotes support for the status $\begin{array}{lllll}\text { quo. Journal of Personality and Social Psychology, 109(5), } & 739 .\end{array}$ http://dx.doi.org/10.1037/pspa0000033 
Hussak, L. J., \& Cimpian, A. (2018). Memory accessibility shapes explanation: Testing key claims of the inherence heuristic account. Memory \& Cognition, 46(1), 68-88. http://dx.doi.org/10.3758/s13421017-0746-8

Kreidl, M. (2000). Perceptions of poverty and wealth in western and post-communist countries. Social Justice Research, 13(2), 151-176. https://dx.doi.org/10.1023/A:1007597807110

Leahy, R. L. (1981). The development of the conception of economic inequality: I. Descriptions and comparisons of rich and poor people. Child Development, 52, 523-532. http://dx.doi.org/10.2307/1129170

Leahy, R. L. (1983). Development of the conception of economic inequality: II. Explanations, justifications, and concepts of social mobility and change. Developmental Psychology, 19(1), 111. http://dx.doi.org/10.1037/0012-1649.19.1.111

Lott, B. (2002). Cognitive and Behavioral Distancing From the Poor. American Psychologist, 57(2), 100-110. http://dx.doi.org/10.1037/0003-066X.57.2.100

Miller, P.H \& Aloise, P.A. (1989). Young Children's Understanding of the Psychological Causes of Behavior: A Review. Child Development, 60(2), 257-285. http://dx.doi.org/10.2307/1130975

Miller, P. H., \& Aloise - Young, P. A. (2018). Revisiting young children's understanding of the psychological causes of behavior. Child development, 89(5), 1441-1461. http://dx.doi.org/10.1111/cdev.12891

Monteiro, M. B. (2002). A construção da exclusão social nas relações interétnicas: Orientações teóricas e de investigação na perspectiva do desenvolvimento. Psicologia, 16(2), 271-292. http://dx.doi.org/10.17575/rpsicol.v16i2.481

Monteiro, M. B., França, D. X., e Rodrigues, R. (2009). The development of intergroup bias in childhood: How social norms can shape children's racial behaviours. International Journal of Psychology, 44, 29-39. http://dx.doi.org/10.1080/00207590802057910

Muthén, L.K. and Muthén, B.O. (1998-2012). Mplus User's Guide. Seventh Edition. Muthén \& Muthén.

Nesdale, D. (2004). Social identity processes and children's ethnic prejudice. In M. Bennett, \& F. Sani (Eds.), The development of the social self (pp. 219-246). Psychology Press.

OCDE (2017), Poverty rate (indicator). . http://dx.doi.org/10.1787/0fe1315d-en

Olson, K. R., Dunham, Y., Dweck, C. S., Spelke, E. S., \& Banaji, M. R. (2008). Judgments of the lucky across development and culture.Journal of Personality and Social Psychology,94(5), 757. http://dx.doi.org/10.1037/0022-3514.94.5.757

Olson, K.R., Banaji, M.R., Dweck, C.S. \& Spelke, E.S. (2006). Children's Biased Evaluations of Lucky Versus Unlucky People and Their Social Groups. Psychological, 17(10), 845-846. http://dx.doi.org/10.1111/j.1467-9280.2006.01792.x

Ramsey, P. G. (1991). Young children's awareness and understanding of social class differences. Journal of Genetic Psychology, 152, 71-82. http://dx.doi.org/10.1080/00221325.1991.9914679

Rhodes, M., Leslie, S.J., Saunders, K., Dunham, Y., \& Cimpian, A. (2018). How does social essentialism affect the development of inter - group relations?.Development Science, 21, e12509. http://dx.doi.org/10.1111/desc.12509

Rholes, W.S. \& Ruble, D.N. (1984). Children's Understanding of Dispositional characteristics of others. Child Development, 55, 550-560. http://dx.doi.org/10.2307/1129966

Ridge, T. (2002). Childhood poverty and social exclusion: From a child's perspective. Policy press.

Rodrigues, R. B., Monteiro, M. B., \& Rutland, A. (2012). O que pensam e dizem crianças portuguesas "Brancas" sobre grupos "raciais"? O papel de duas normas grupais conflituantes na expressão e inibição do preconceito na infância. In J. H. António \& V. Policarpo (Eds.), Os imigrantes e a imigração aos olhos dos Portugueses: Manifestações de preconceito e perspectivas sobre a inserção de imigrantes (pp. 185-220). Fundação Calouste Gulbenkian

Rodrigues, R. B., Rutland, A., e Collins, E. (2016). The multi-norm structural social-developmental model of children's intergroup attitudes: Integrating intergroup-loyalty and outgroup fairness norms. In Vala, J., Calheiros, M. \& Waldzus, S. (Eds.). The Social Developmental Construction of Violence and Intergroup Conflict (pp. 219-246). Springer.

Ruble, D.N., Feldman, N.S., Higgins, E. e Karlovac, M. (1979). Locus of causality and use of information in the development of causal attributions. Journal of Personality. 47, $595 \quad-614$. https://dx.doi.org/10.1111/j.1467-6494.1979.tb00211.x.

Sigelman, C. K. (2012). Rich man, poor man: Developmental differences in attributions and perceptions. Journal of Experimental Child Psychology, $113, \quad 415-429$. http://dx.doi.org/10.1016/j.jecp.2012.06.011

Sigelman, C. K. (2013). Age differences in perceptions of rich and poor people: is it skill or luck?. Social Development, 22(1), 1-18. http://dx.doi.org/10.1111/sode.12000 
Tagler, M. J., \& Cozzarelli, C. (2013). Feelings toward the poor and beliefs about the causes of poverty: The role of affective-cognitive consistency in help-giving. The Journal of Psychology, 147(6), 517-539. http://dx.doi.org/10.1080/00223980.2012.718721

Vala, J. (2005). A análise de conteúdo. In Silva, A. S., \& Pinto, J. M. (13a Ed.). Metodologia das ciências sociais. (101-128). Edições Afrontamento.

Vala, J., Lima, M. \& Lopes, D. (2004). Social values, prejudice and solidarity in the European Union. In W. Arts \& L. Halman (Eds.), European Values at the End of the Millenium (pp. 139-163). Brill.

Weiner, B., Osborne, D. \& Rudolph, U. (2011). An attributional analysis of reactions to poverty: The political ideology of the giver and the perceived morality of the receiver. Personality and Social Psychology Review, 15(2) 199-213. http://dx.doi.org/10.1177/1088868310387615

White, E. S., Mistry, R. S., \& Chow, K. A. (2013). How do teachers talk about economic inequality? The complexity of teaching at a socioeconomically integrated elementary school. Analyses of Social Issues and Public Policy, 13(1), 370-394. http://dx.doi.org/10.1111/asap.12024

Woods, T. A., Kurtz-Costes, B., \& Rowley, S. J. (2005). The development of stereotypes about the rich and poor: Age, race, and family income differences in beliefs. Journal of Youth and Adolescence, 34, 437445. http://dx.doi.org/10.1007/s10964-005-7261-0

$\begin{array}{ll}\text { Historial do artigo } \\ \text { Recebido } & 05 / 2018 \\ \text { Aceite } & 11 / 2019 \\ \text { Publicado } & 12 / 2020\end{array}$


Atribuições causais e soluções percebidas para a pobreza na infância 